\title{
Evaluating Reading Diagnostic Tests: An Application of Confirmatory Factor Analysis To Multitrait-Multimethod Data
}

\author{
Herbert W. Marsh and Susan Butler \\ The University of Sydney
}

\begin{abstract}
Diagnostic reading tests, in contrast to achievement tests, claim to measure specific components of ability hypothesized to be important for diagnosis or remediation. A minimal condition for demonstrating the construct validity of such tests is that they are able to differentiate validly between the reading traits that they claim to measure (e.g., comprehension, sound discrimination, blending). This condition is rarely tested, but multitrait-multimethod (MTMM) designs are ideally suited for this purpose. This is demonstrated in two studies based on the 1966 version of the Stanford Diagnostic Reading Test (SDRT). In each study, the application of the Campbell-Fiske guidelines and confirmatory factor analysis (CFA) to the MTMM data indicated that the SDRT subscales could be explained in terms of a method/halo effect and a general reading factor that was not specific to any of the subscales; this refutes the construct validity of the 1966 version of the SDRT as a diagnostic test. Other diagnostic tests probably suffer the same weakness and should also be evaluated in MTMM studies.
\end{abstract}

Reading achievement tests measure overall reading performance. In contrast, diagnostic tests are designed to analyze specific strengths and weaknesses in particular areas of reading that are hypothesized to be important for diagnosis or remediation. Diagnostic tests result in separate subscale scores, and interpretations are based on differences between subscales or on a profile of the scores. Authors of measurement textbooks (e.g., Anastasi,

APPLIED PSYCHOLOGICAL MEASUREMENT

Vol. 8, No. 3, Summer 1984, pp. 307-320

(C) Copyright 1984 Applied Psychological Measurement Inc. 0146-6216/84/030307-14\$1.95
1976; Cronbach, 1970; Thorndike \& Hagen, 1977) point to the difficulties inherent in the interpretation of profiles and difference scores. The most obvious cause of such difficulties might be a diagnostic test's failure to measure differentially the skills in the various areas that it claims to assess. Anastasi (1976) discussed this problem in more detail, indicating that different diagnostic tests vary substantially in the quality of their design. She described the 1966 version of the Stanford Diagnostic Reading Test (SDRT; Karlsen, Madden, \& Gardner, 1966) as an example of a diagnostic test that is well constructed.

The demonstration of the validity of a diagnostic test requires (1) that it is able to differentiate validly between components that it claims to measure, and (2) that these components are useful for diagnosis or remediation. The satisfaction of the first condition is prerequisite for satisfaction of the second, and thus serves as a necessary but not sufficient condition for demonstrating the construct validity of a diagnostic test. However, there are no commonly employed strategies that are effective for testing this condition, though test manuals often do report the reliability of each subscale and the correlations among the different subscales. A superior approach that has not been widely used in evaluating diagnostic tests (Coles, 1978) is the application of multitrait-multimethod (MTMM) studies (Campbell \& Fiske, 1959; Marsh, Barnes, \& Hocevar, in press; Marsh \& Hocevar, 1983). With this approach, multiple traits (e.g., the diagnostic 
test subscales) are each assessed by different methods (e.g., results from different tests, ratings by teachers or experts).

Convergence or convergent validity refers to agreement between multiple methods of assessing the same trait. Divergence or discriminant validity provides a test of whether agreement between multiple indicators of the same trait can be explained in terms of a generalized agreement that incorporates all the subscales, or whether the agreement is specific to the content of the particular trait. If a reading diagnostic test has little or no discriminant validity, then it does not satisfy the first condition for demonstrating the validity of diagnostic tests and has little value as a diagnostic tool, even though it may still provide a valid indication of overall reading ability.

Campbell and Fiske (1959) argued that the level of generality that can be inferred from convergence falls along a continuum where the extremes represent reliability (two maximally similar methods) and validity (two maximally dissimilar methods). In some MTMM studies the "different" methods are really quite similar (e.g., alternative forms, split-halves, or test-retest data) and convergence refers to a level of generality that is normally described as reliability or stability. Other MTMM studies employ methods that are quite distinct (e.g., test scores, teacher ratings, and student self-reports) and convergence refers to a level of generality that is more commonly described as validity. However, it is important to recognize that MTMM analysis can legitimately be applied in each type of study, and that the actual mechanics of the analysis will be the same whether the "different" methods are quite similar or quite dissimilar. Marsh et al. (in press) discussed this distinction, arguing that MTMM studies that simultaneously assess several types of method variation in the same design provide a stronger basis for the examination of construct validity than do studies based on just one source of method variation.

\section{The Present Investigation}

The purposes of this investigation were to describe the design of MTMM studies for the evaluation of diagnostic tests, and to demonstrate dif- ferent procedures for analyzing the MTMM data. This investigation examined the discriminant validity of the SDRT subscales, and tested their ability to distinguish between the different components of reading that the test claims to measure.

The data came from two previously published studies in which the five subscales that are common to Levels I and II of the 1966 version of the SDRT were administered. The SDRT was chosen because it appeared to be the best diagnostic reading test available in Australia, and it is considered to be a well-constructed diagnostic reading test (Anastasi, 1976; also see review by Kasdon, 1972). Subsequently, a different version of the SDRT has been developed (see review by van Roekel, 1978), so findings of this study that refer to the effectiveness of the SDRT may not generalize to the newer version.

\section{Study 1}

\section{Method}

Materials and procedures. The materials, procedures, and sample for this longitudinal study are described elsewhere in more detail (Butler \& Marsh, 1983; Butler, Marsh, Sheppard, \& Sheppard, 1982, 1983 , in press) and so are summarized only briefly here. A battery of tests was administered in kindergarten in 1974 and various reading achievement and academic measures were collected in 1975 , 1976, 1977, and 1980. The primary focus of the present study was on the five SDRT subscales that are common to Levels I and II of the test (administered in 1977 and 1980) and on teacher ratings designed to parallel the SDRT subscales (collected only in 1980). In addition to the MTMM analyses, the relationships between the SDRT and other criteria were examined. These criteria include (1) total reading scores, representing a weighted average of reading tests administered in 1975 and 1976 (see Butler et al., 1982, 1983, in press); (2) results from the Schonell Graded Word Reading test (Schonell \& Schonell 1955) for 1977 and 1980; and (3) the end-of-year-six assessments in language and mathematics for 1980 (the results of a standardized assessment conducted in all public schools in the state of New South Wales). SDRT summary scores were computed by taking the sum of the five subscale 
scores after each had been standardized to have a mean $=0.0$ and a standard deviation of 1.0 . Teachers, in addition to rating the five specific components of reading, also judged overall reading ability.

Sample. In 1974 the initial sample consisted of all kindergarten pupils in seven schools from the St. George area of metropolitan Sydney. (In New South Wales, kindergarten is the first year of mandatory schooling.) This public school district was chosen because it was felt to be representative of the diversity of socioeconomic levels and cultural backgrounds in metropolitan Sydney, and the results of the standardized measures and the endof-year-six assessments suggested that the mean academic ability of these children was about average.

At the start of the study, tests were administered to 392 children ( $52 \%$ males) who varied in age from 5.0 to 7.1 years (mean age $=5.6$ years). In subsequent years, materials were administered whenever a child from the sample could be located. A child was dropped from the study only in those cases when he/she moved out of the state or when no forwarding address was provided. Results in the present analysis are based on the 286 children from the original sample who were also tested in 1980 , but a check indicated that the other 106 children who were in the original sample did not differ from this sample in terms of intelligence scores, which were collected for all subjects in 1974 (Butler \& Marsh, 1983; Butler et al., 1982, 1983, in press).

\section{Results}

Campbell-Fiske guidelines. The MTMM matrix (Table 1) represents correlations among $15 \mathrm{var}-$ iables - the five reading traits measured by the SDRT in 1977 and again in 1980, and by the parallel set of teacher ratings from 1980. Application of the

'Campbell and Fiske (1959; also see Marsh et al., in press; Marsh \& Hocevar, 1983, 1984) proposed four guidelines for examining MTMM matrices. These are: (1) convergent validities, correlations between multiple indicators of the same trait, should be statistically significant and substantial; (2) convergent validities should be higher than other correlations in the same row or same column of the same square submatrix (i.e., the
Campbell-Fiske guidelines ${ }^{1}$ to this MTMM matrix reveals that:

1. Convergence coefficients (the underlined values in the diagonals of the square submatrices) are statistically significant and substantial (mean $r=.57$ ), offering support for the first guideline that demonstrates the convergent validity of the reading trait measures.

2. Convergent validity coefficients (mean $r=$ .57) are only slightly higher than other correlations in the square submatrices (mean $r$ $=.53$ ), and only 3 of the 15 are higher than the other 8 correlations in the same row or column of the square submatrix. Thus, support is weak for the second guideline and this aspect of divergent validity.

3. Convergent validity coefficients for the two administrations of the SDRT (mean $r=.60$ ) are only slightly higher than the correlations among the different scales within either administration (in the triangular submatricesmean $r=.53$ ), and none of the five convergent validities is higher than all eight correlations involving the same scale. Convergent validities representing agreement between teacher ratings and test scores (mean $r=.56$ ) are substantially lower than correlations among teacher ratings of the different subscales (mean $r=.90$ ). These results fail to support the third guideline or this aspect of discriminant validity, and suggest a large method/halo effect.

4. Correlations between reading comprehension and the other traits are consistently large and suggest a general reading factor, which is best represented by this scale.

The application of the Campbell-Fiske guidelines offers good support for the convergent validity of the SDRT subscales, but not for their discriminant validity. Instead, the convergent validity for each trait appears to be a function of agreement

heterotrait-heteromethod block); (3) convergent validity for each variable should be higher than correlations between that variable and other variables in the same row or column of the corresponding triangular submatrices (i.e., the heterotrait-monomethod block); and (4) the pattern of correlations in each of the submatrices should be similar. 


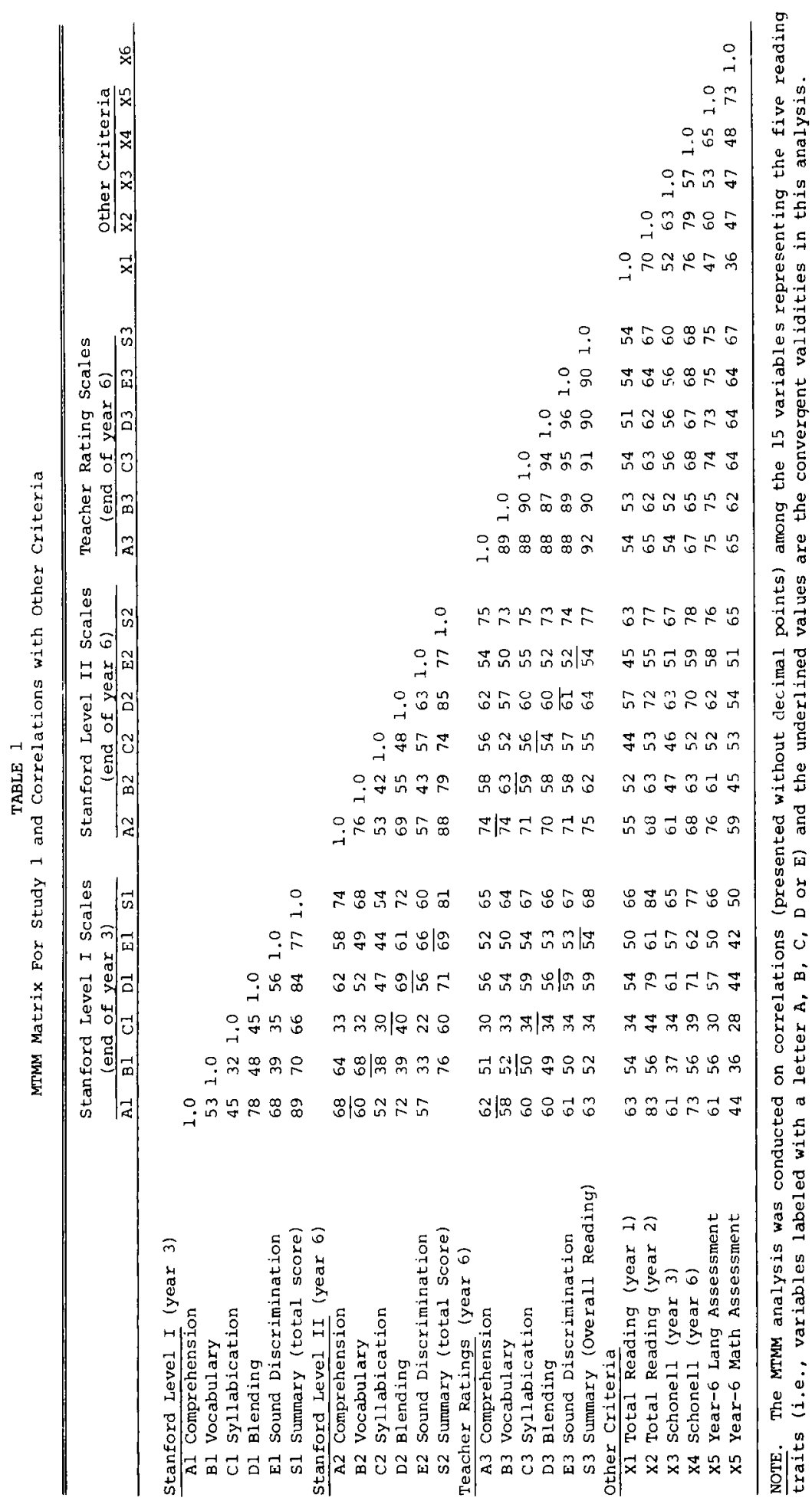


on a general reading factor that incorporates each of the different subscales. ${ }^{2,3}$

Correlations among the three summary scores (mean $r=.75$ ) are also higher than any of the 15 convergent validities. Even within each of the square submatrices, none of the convergent validities exceeds the correlations involving the same variable and the summary scores. These findings further argue that convergent validity for each specific subscale is a function of agreement on a generalized reading factor and not on the specific content of that subscale.

Confirmatory factor analysis (CFA). The Campbell-Fiske guidelines are informative and widely used, but recent methodological advances have emphasized the use of CFA in MTMM studies

${ }^{2}$ Interpretations based on the Campbell-Fiske guidelines are complicated by the fact that the reliabilities of various traits may differ. Some researchers suggest that correlations should be corrected for attenuation while others argue that this is generally not appropriate. However, this is not a problem with the CFA of MTMM data since the reliabilities of measured variables and factors are estimated, and coefficients are corrected for unreliability as part of the analysis.

\footnotetext{
${ }^{3} \mathrm{An}$ anonymous reviewer noted that the SDRT is designed to differentiate among poor readers so that many of the subtests have a large number of easy items, and this results in skewed distributions that may affect the observed correlations. This is most likely to have a noticeable effect when the measured variables are differentially skewed. The reviewer suggested that this potential problem could be remedied by normalizing scores for each of the subscales before computing correlations in the MTMM matrix. The problem is also troublesome in the CFA of MTMM data where the effect of violations in assumptions of normality on maximum likelihood statistics is not well understood. For comparisons based on two sets of scores from the same test (e.g., Levels I \& II of the SDRT) differentially skewed distributions are likely to bias the results in favor of demonstrating discriminant validity, since the same subscale will probably have a similar skew on both versions of the same test. Furthermore, in the present application, the lack of discriminant validity for the SDRT subscales resulted not from low convergent coefficients that might be attributable to differentially skewed distributions, but from the large correlations among scores that were designed to measure different traits; these would become even larger if differential skews did affect the correlations and the scores were normalized. Consequently, substantive conclusions in this investigation are unlikely to be influenced by this problem, but it may be an important issue in other applications.
}

(see Kenny, 1979; Marsh et al., in press; Marsh \& Hocevar, 1983, 1984; Schmitt, Coyle, \& Saari, 1977). For this approach, MTMM matrices are factor analyzed and the results are used to infer the underlying constructs. High loadings on factors defined by multiple indicators of the same reading trait support the construct validity of the trait. High loadings on factors defined by variables measured with the same method argue for a method/halo effect. High loadings on a single factor defined by all measured variables argue for a general reading factor. With CFA the researcher can specify alternative models and test their ability to describe the data (Jöreskog, 1969, 1974; Marsh et al., in press; Marsh \& Hocevar, 1983, 1984). Thus, the MTMM analysis can be viewed as a special application of CFA with a priori factors that correspond to methods and traits.

The MTMM application considered here consisted of five trait factors (the reading traits) and three method factors (the two sets of SDRT scores, and the one set of teacher ratings), and all eight factors appeared in the first CFA model. CFA performed with LISREL V (Jöreskog \& Sörbom, 1981) requires the specification of three matrices that are conceptually similar to matrices resulting from traditional/exploratory factor analyses: Lambda $Y$, the matrix of factor loadings; Psi, the matrix of correlations among factors; and Theta Epsilon, a diagonal matrix of error/uniquenesses that are similar to one minus the communality estimates. In the CFA models considered here:

1. Factor loadings in Lambda $Y$ are constrained to define a priori trait and method factors. For each factor, one measured variable is designated to be a reference variable and its factor loading is set to be 1.0 , other factor loadings for variables designed to measure the factor are free to be estimated by CFA procedure, and all other factor loadings are fixed or constrained to be zero.

2. Correlations among the factors in Psi are constrained so that correlations between trait and method factors are zero, while correlations among method factors and among trait factors are free to be estimated. Factor variances in 
the diagonal of the Psi matrix are also estimated.

3. The error/uniquenesses in Theta Epsilon are constrained to form a diagonal matrix so that the error terms are uncorrelated.

Model 1, with three method factors and five trait factors, is the standard model used in MTMM studies. However, it failed to reach a stable solution (i.e., to converge) after 500 iterations, and this typically indicates a problem with the data. Despite the fact that the model did not converge, LISREL $\mathrm{V}$ still provided parameter estimates for Model 1. Although these estimates must be interpreted cautiously, they may still provide insight as to why the model did not converge. In this application, each of the three method factors was well defined in that all the factor loadings and factor variances were statistically significant. However, the five trait factors were not well defined, and only the first two had factor variances that differed significantly from zero. This finding suggests that trait factors 3,4 , and 5 did not measure any reliable variance, as well as providing a likely explanation for why Model 1 failed to reach a stable solution and arguing against the discriminant validity of these reading traits.

Based on the suggestion that three of the trait factors account for no variance, Model 2 hypothesized that each of the measured variables used to define these three trait factors is explained in terms of a method/halo effect alone (plus error/uniqueness). Thus, the model contained only two trait factors.

Inspection of the parameter values for Model 2 (Table 2) provides a better understanding of the CFA model. Parameters with the values of 1.0 or 0.0 are fixed in order to define the CFA model in accordance with the description presented earlier, while all other parameters are free to be estimated. Each method factor is defined by measured variables assessed by the same method, while each trait factor is defined by multiple indicators of the same trait. The pattern of parameters in Model 1 differed from Model 2 only in that multiple indicators of Traits 3 to 5 defined three additional trait factors. In Model 2, unlike Model 1, most of the factor loadings and all of the factor variance estimates are statistically significant, and Model 2 required only a small number of iterations to reach a stable solution. The goodness-of-fit indices that are described below also indicate that Model 2 provides a reasonable fit to the data. Thus, Model 2 is preferable to Model 1.

The LISREL V program, after testing for identification, attempts to minimize a likelihood function that is based on differences between the original and reproduced correlation matrices, and it provides an overall chi-square goodness-of-fit test. However, this goodness-of-fit test is strongly influenced by sample size, so that a reasonably good fit will be rejected if based on a large sample size, while a poor fit will be accepted if based on a small sample size. Alternative goodness-of-fit indices include (1) the ratio of the chi-square to the degrees of freedom, (2) the mean square residual (MSR) based on differences between the original and reproduced correlation matrices (see Jöreskog \& Sörbom, 1981), and (3) coefficient delta (Bentler \& Bonett, 1980), which scales the goodness-of-fit along a continuum that varies between 0 and 1 . None of these indices of goodness-of-fit has been universally endorsed (see Bentler \& Bonett, 1980; Fornell, 1983; Marsh et al., in press; Marsh \& Hocevar, 1983, 1984), and each is considered in evaluating the alternative models described below.

Further alternative models were proposed to describe the MTMM data, and their ability to fit the data is summarized in Table 3 . The null model (Model 0) is used to define the zero point for coefficient delta, and proposes that each of the 15 measured variables represents a separate factor that is uncorrelated with other factors. Model 1, as described earlier, did not converge and so no goodness-of-fit indices are presented for it. Model 2, whose parameter estimates appear in Table 2, provides a reasonable fit to the data. Models that hypothesized either a single general reading factor with no specific trait or method factors (Model 3), three method factors but no trait factors (Model 4), or five trait factors but no method factors (Model 5) each did substantially less well than Model 2, though the method-factor-only model (Model 4) provides a reasonable fit to the data. Model 6 proposed three method factors and one general reading 
TABLE 2

Confirmatory Factor Analysis Parameter Estimates for Model 2 in Study 1

\begin{tabular}{|c|c|c|c|c|c|c|}
\hline \multirow{2}{*}{$\begin{array}{l}\text { Measured } \\
\text { Variables }\end{array}$} & \multicolumn{5}{|c|}{ LAMBDA Y (Factor Loadings) } & \multirow{2}{*}{$\begin{array}{c}\text { Error/ } \\
\text { Uniqueness }\end{array}$} \\
\hline & $\mathrm{MI}$ & $\mathrm{M} 2$ & M3 & $\mathrm{Tl}$ & $\mathrm{T} 2$ & \\
\hline \multicolumn{7}{|l|}{ SDRT Level I (MI) } \\
\hline MlTl Comprehension & 1.0 & .00 & .00 & .07 & .00 & $.18 *$ \\
\hline MlT2 Vocabulary & $.61 *$ & .00 & .00 & .00 & $.99 *$ & $.38 *$ \\
\hline M1T3 syllabication & $.54 \star$ & .00 & .00 & .00 & .00 & $.75 \star$ \\
\hline MlT4 Blending & $.92 *$ & .00 & .00 & .00 & .00 & $.29 *$ \\
\hline M1T5 Sound Discrim. & $.82 \star$ & .00 & .00 & .00 & .00 & $.45 \star$ \\
\hline \multicolumn{7}{|l|}{ SDRT Level II (M2) } \\
\hline M2Tl Comprehension & .00 & $1.25 *$ & .00 & 1.0 & .00 & $.08^{\star}$ \\
\hline M2T2 vocabulary & .00 & $1.02 *$ & .00 & .00 & 1.0 & .24 夫 \\
\hline M2T3 Syllabication & .00 & 1.0 & .00 & .00 & .00 & $.58 *$ \\
\hline M2T4 Blending & .00 & $1.29 *$ & .00 & .00 & .00 & $.31 \star$ \\
\hline $\begin{array}{r}\text { M2T5 Sound Discrim. } \\
\text { Teacher Ratings (M3) }\end{array}$ & \multicolumn{5}{|c|}{ Teacher Ratings (M3) } & $.48 \star$ \\
\hline M3T1 Comprehension & .00 & .00 & .91 & $.23^{*}$ & .00 & $.16 \star$ \\
\hline M3T2 Vocabulary & .00 & .00 & .91 & .00 & $.30 *$ & $.14^{\star}$ \\
\hline M3T3 Syllabication & .00 & .00 & .99 & .00 & .00 & $.06 \star$ \\
\hline M3T4 Blending & .00 & .00 & .99 & .00 & .00 & $.06 *$ \\
\hline M3T5 Sound Discrim. & .00 & .00 & 1.0 & .00 & .00 & $.04 \star$ \\
\hline \multicolumn{7}{|l|}{ Factors } \\
\hline Ml SDRT Level I & $.82 \star$ & & & & & \\
\hline M2 SDRT Level II & $.54 *$ & $.42 *$ & & & & \\
\hline M3 Teacher Ratings & $.63 *$ & $.51 *$ & $.96^{\prime}$ & & & \\
\hline Tl Comprehension & .00 & .00 & .00 & $.24 *$ & & \\
\hline T2 Vocabulary & .00 & .00 & .00 & $.21 *$ & $.30 *$ & \\
\hline \multicolumn{7}{|l|}{$\star p<.05$} \\
\hline $\begin{array}{l}\text { Note. Parameters with } \\
\text { the CFA model, and thus } \\
\text { these parameters. LISR } \\
\text { significance for all ot }\end{array}$ & $\begin{array}{l}\text { values } \\
\text { there } \\
\text { EL prov } \\
\text { her par }\end{array}$ & $\begin{array}{l}\text { f } 1.0 \text { ol } \\
\text { re no t } \\
\text { des est }\end{array}$ & $\begin{array}{l}.00 \text { we } \\
\text { ts of }\end{array}$ & $\begin{array}{l}\text { e fixe } \\
\text { tatist } \\
\text { d test }\end{array}$ & $\begin{array}{l}\text { in orde } \\
\text { al sigr } \\
\text { of stat }\end{array}$ & $\begin{array}{l}r \text { to define } \\
\text { ificance for } \\
\text { istical }\end{array}$ \\
\hline
\end{tabular}

factor that was defined by all 15 measured variables. This model provides a good fit to the data and one that is superior to Model 2 (i.e., the difference in chi-square values for the two models is statistically significant when evaluated against the difference in degrees of freedom).

Inspection of the goodness-of-fit indices for the alternative models, and particularly for Model 6 , demonstrates the lack of discriminant validity for the reading traits. Model 6 proposed that each measured variable can be explained in terms of method variance and a single, general reading factor that incorporates all the different subscales. In Model 6 all the measured variables load significantly on the general reading factor, demonstrating that this factor does reflect all the measured variables. Model 6 also provides a better fit to the data than do any of the models that propose specific trait factors.

Thus, while the CFA of the MTMM data provides a more rigorous test than the Campbell-Fiske guidelines, the conclusions are similar. However, the strongest evidence against the discriminant validity of the reading traits came from the CFA Model 6 , defined by just method factors and a general factor, and support for such a model could not easily be inferred simply from the application of the Campbell-Fiske guidelines. Such a model is particularly useful in evaluating diagnostic tests, and demonstrates the flexibility of the CFA approach for this purpose. 
Correlations with other criteria. The other criteria considered in Study 1 (see Table 1) include five measures of reading/language, and each is substantially correlated with the three summary scores representing the two sets of SDRT scores and the set of teacher ratings (mean $r=.70$ ). This demonstrates that summary scores for the SDRT, as well as for teacher ratings, are quite effective at differentiating among subjects in terms of overall reading performance. Only one variable in Table 1 , the end-of-year-six assessment in mathematics, is specifically not a reading measure. Although this score is substantially correlated with the reading measures, the three summary reading scores are more highly correlated with other measures of reading/language than with this measure. This suggests that the reading scores are measuring a characteristic that can be differentiated from mathematical achievement.

\section{Study 2}

\section{Method}

Materials. The materials and sample for Study 2 are also described elsewhere in more detail (Marsh, Smith, Barnes, \& Butler, 1983), and so are summarized only briefly here. The measures were col- lected near the middle of Grade 4 (Time 1) and/or again near the end of Grade 4 (Time 2). As in Study 1 , the focus was on the five reading traits assessed by the SDRT (Time 2 only) and the corresponding teacher ratings (Time $1 \&$ Time 2). Additional criteria included results from the GAP Reading test (McLeod, 1977), teacher ratings of mathematics ability, student self-concepts in reading and mathematics (Marsh et al., 1983), and an objective mathematics test which was administered at Time 2 only. Summary scores for the SDRT and teacher ratings were defined as in Study 1.

Sample. The sample (see Marsh et al., 1983) consisted of five fourth-grade classes from two Catholic primary schools in Sydney, Australia. The children varied in age from 8 to 11 years, came from predominantly middle-class families, and were about average in terms of academic ability. Results of this study are based on responses from 150 children (out of the original sample of 152) who were tested both at Time 1 and at Time 2 .

\section{Results}

The application of the Campbell-Fiske guidelines to the MTMM data in Study 2 (Table 4) was

TABLE 3

Goodness of Fit Indices for Alternative Models in Study 1

\begin{tabular}{|c|c|c|c|c|c|}
\hline Model Description & $\begin{array}{l}\text { Chi- } \\
\text { square }\end{array}$ & df. & $\begin{array}{l}\text { Chi-square/ } \\
\text { df ratio }\end{array}$ & RMS & $\begin{array}{l}\text { İficient } \\
\text { Delta }\end{array}$ \\
\hline O. Null Model & 4687 & 135 & 34.72 & .554 & .000 \\
\hline $\begin{array}{l}\text { 1. } 3 \text { method factors, } \\
5 \text { trait factors }\end{array}$ & & id no & converge; see & discussion) & \\
\hline $\begin{array}{l}\text { 2. } 3 \text { method factors, } \\
2 \text { trait factors }\end{array}$ & 260 & 80 & 3.25 & .046 & .944 \\
\hline $\begin{array}{l}\text { 3. } 1 \text { general factor (no } \\
\text { method or trait factors) }\end{array}$ & 1023 & 90 & 11.37 & .112 & .782 \\
\hline $\begin{array}{l}\text { 4. } 3 \text { method factors, } \\
\text { no trait factors }\end{array}$ & 431 & 87 & 4.95 & .052 & .908 \\
\hline $\begin{array}{l}\text { 5. } 5 \text { trait factors, } \\
\text { no method factors }\end{array}$ & 871 & 80 & 10.89 & .104 & .814 \\
\hline $\begin{array}{l}\text { 6. } 3 \text { method factors, } \\
1 \text { general factor \& } \\
\text { no trajt factors }\end{array}$ & 236 & 72 & 3.28 & .030 & .950 \\
\hline
\end{tabular}




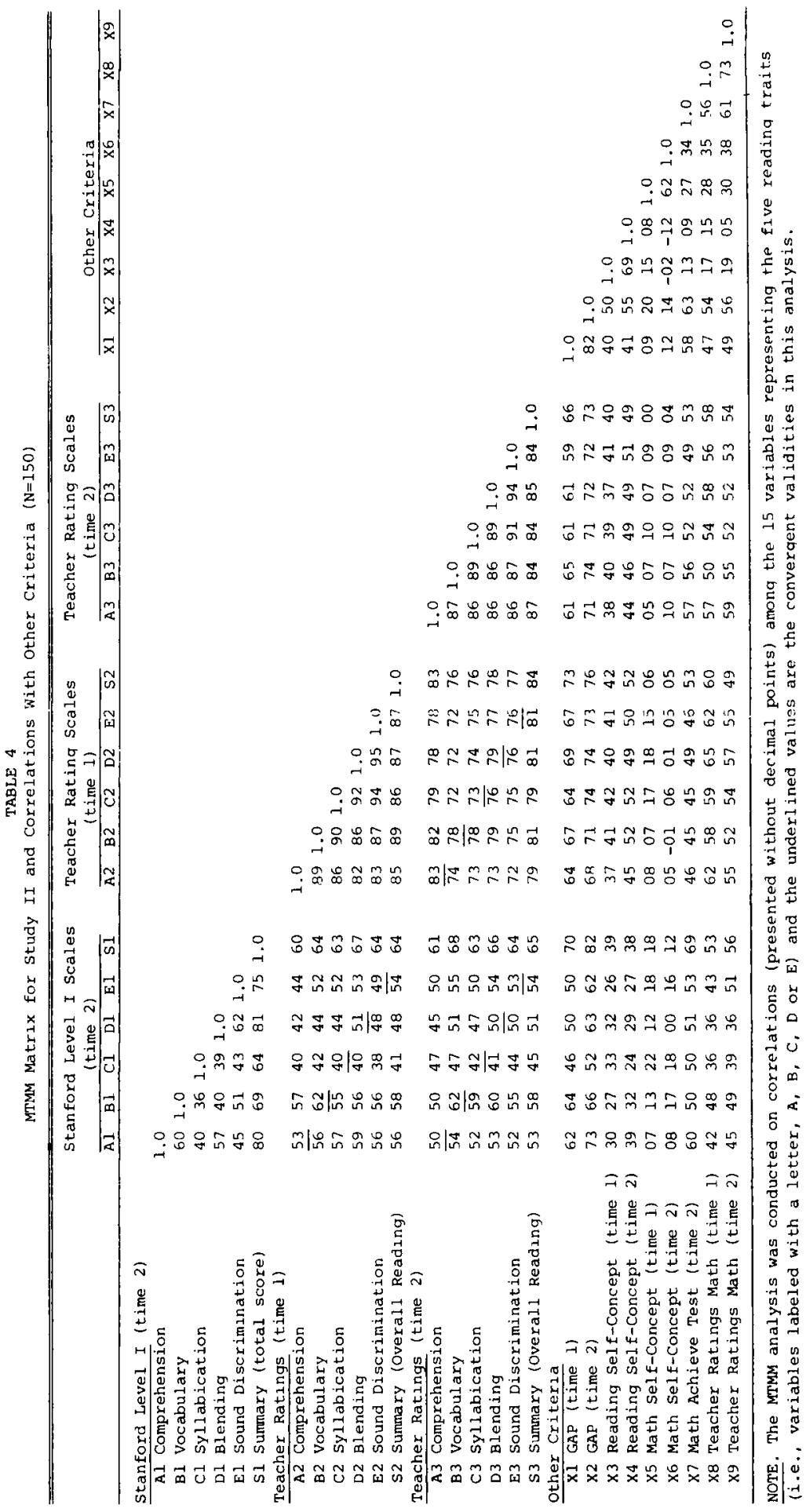


similar to the application in Study 1, and revealed that:

1. Convergence coefficients (mean $r=.60$ ) are substantial, though agreement between teacher ratings at Time 1 and 2 (mean $r=.78$ ) is higher than between teacher ratings and test scores (mean $r=.51$ ). These results satisfy the first Campbell-Fiske guideline, which demonstrates the convergent validity of the traits.

2. Convergence coefficients (mean $r=.60$ ) are nearly the same as other correlations in the square submatrices (mean $r=.59$ ) and this pattern is similar for each of the three submatrices. Only 3 of the 15 convergence coefficients are higher than the other 8 correlations in the same row or column of the same square submatrix. Hence, support is weak for the second Campbell-Fiske guideline and this aspect of discriminant validity.

3. Convergent validities for the SDRT subscales (mean $r=.51$ ) are only slightly higher than correlations among different subscales for the test (mean $r=.46$ ) and are substantially less than correlations among the teacher ratings (mean $r=.88$ ). Convergent validities relating the two sets of teacher ratings $(r=.78)$ are also lower than correlations among the teacher ratings of the different subscales (mean $r=$ .88). These findings suggest a large method/ halo effect, and fail to support the third Campbell-Fiske guideline or this aspect of discriminant validity.

4. There is no apparent pattern of correlations among the reading traits that is consistent across the submatrices.

Application of the Campbell-Fiske guidelines offers good support for the convergent validity of the SDRT subscales, but not for their discriminant validity. As in Study 1, inspection of correlations with the summary scores further suggests that the convergent validity is a function of an overall agreement on a general reading factor and is not specific to the content of each subscale.

CFA of the MTMM data. The CFA models described here are the same as in Study 1 except that the three method factors in Study 2 represented teacher ratings on two occasions and one administration of the SDRT. As in Study 1, the model containing three method factors and five trait factors (Model 1) failed to converge, and inspection of the parameter values again suggested that Traits 3 to 5 measured no reliable variance. Inspection of the parameter estimates for Model 2 (Table 5) indicates that most of the factor loadings and the factor variance estimates are statistically significant, and Model 2 converged on a solution after relatively few iterations. Also, the goodness-of-fit indices for Model 2 (Table 6) are reasonable. Thus, Model 2 is preferable to Model 1.

Inspection of the goodness-of-fit indices for the alternative models (Table 6) results in conclusions similar to those from Study 1. The chi-square values for Study 2 are smaller than in Study 1, but this is primarily a function of the difference in sample sizes. Again, Model 2 fits the data better than Models 3 to 5 , while Model 6 provides the best fit. In Model 6 each measured variable is explained in terms of a method/halo effect and a generalized reading factor that is not specific to any particular reading trait. Consequently, as in Study 1 , these results demonstrate the lack of discriminant validity for the reading traits.

Correlations with other criteria. Correlations between the reading summary scores and other criteria (Table 4) provide further information about the validity of the reading measures. Scores from the GAP reading test are substantially correlated with both the SDRT summary score and teacher ratings of overall reading ability. Student self-concepts in reading are also significantly correlated with the SDRT summary score, teacher ratings, and the GAP scores. The GAP scores are more highly correlated with teacher ratings of overall reading ability and with student self-concepts in reading than is the SDRT summary score; this is surprising since the GAP appears to be less comprehensive and is a much shorter test than the SDRT.

Five measures of mathematical achievement (Table 4) are substantially correlated with each other, and less correlated with the reading measures. Similarly, the various reading measures are more highly correlated with each other than with the mathematical measures. Thus, while it appears that read- 
TABLE 5

Confirmatory Factor Analysis Parameter Estimates for Model 2 in Study 2

\begin{tabular}{|c|c|c|c|c|c|c|}
\hline \multirow{2}{*}{$\begin{array}{l}\text { Measured } \\
\text { Variables }\end{array}$} & \multicolumn{5}{|c|}{ LAMBDA Y (Factor Loadings) } & \multirow{2}{*}{$\begin{array}{c}\text { Error/ } \\
\text { Uniqueness }\end{array}$} \\
\hline & $\mathrm{MI}$ & $\mathrm{M} 2$ & M3 & $\mathrm{T} 1$ & $\mathrm{~T} 2$ & \\
\hline \multicolumn{7}{|l|}{ SDRT Level I (MI) } \\
\hline MITl Comprehension & 1.0 & .00 & .00 & .07 & .00 & $.43 \star$ \\
\hline M1T2 Vocabulary & $.88^{\star}$ & .00 & .00 & .00 & $.75 *$ & $.47 *$ \\
\hline MlT3 Syllabication & $.73^{*}$ & .00 & .00 & .00 & .00 & $.70 *$ \\
\hline MIT4 Blending & $.95 *$ & .00 & .00 & .00 & .00 & $.49 *$ \\
\hline MlT5 sound Discrim. & $.93 *$ & .00 & .00 & .00 & .00 & $.51 *$ \\
\hline Teacher Ratings time 1 & (M2) & & & & & \\
\hline M2Tl $\overline{\text { Comprehension }}$ & .00 & $.85 *$ & .00 & 1.0 & .00 & .01 \\
\hline M2T2 Vocabulary & .00 & $.92^{\star}$ & .00 & .00 & 1.0 & $.07 *$ \\
\hline M2T3 Syllabication & .00 & 1.0 & .00 & .00 & .00 & $.07 *$ \\
\hline M2T4 Blending & .00 & $1.01 *$ & .00 & .00 & .00 & $.07 *$ \\
\hline M2T5 Sound Discrim. & .00 & $1.01 *$ & .00 & .00 & .00 & $.05 *$ \\
\hline \multicolumn{7}{|l|}{ Teacher Ratings time 2} \\
\hline M3T1 Comprehension & .00 & .00 & $.91 *$ & $.40 *$ & .00 & $.14^{\star}$ \\
\hline M3T2 Vocabulary & .00 & .00 & $.91 *$ & .00 & $.54^{\star}$ & $.13 *$ \\
\hline M3T3 Syllabication & .00 & .00 & $.97 *$ & .00 & .00 & $.12 *$ \\
\hline M3T4 Blending & .00 & .00 & $.99 *$ & .00 & .00 & $.08^{*}$ \\
\hline M3T5 sound Discrim. & .00 & .00 & 1.0 & .00 & .00 & $.07 *$ \\
\hline \multicolumn{7}{|c|}{ PSI (Factor Correlations) } \\
\hline Ml SDRT Level I & $.57 *$ & & & & & \\
\hline M2 Time 1 Ratings & $.56 *$ & $.93^{\star}$ & & & & \\
\hline M3 Time 2 Ratings & $.56 *$ & $.78 *$ & $.93 *$ & & & \\
\hline Tl Comprehension & .00 & .00 & .00 & $.25 *$ & & \\
\hline T2 vocabulary & .00 & .00 & .00 & $.11 *$ & .11 * & \\
\hline
\end{tabular}

TABLE 6

Goodness of Fit Indices for Alternative Models in Study 2

\begin{tabular}{|c|c|c|c|c|c|}
\hline Model Description & $\begin{array}{l}\text { Chi- } \\
\text { square }\end{array}$ & df & $\begin{array}{l}\text { Chi-square/ } \\
\text { df ratio }\end{array}$ & RMS & $\begin{array}{l}\text { Coefficient } \\
\text { Delta }\end{array}$ \\
\hline O. Null Model & 2976 & 135 & 22.04 & .613 & .000 \\
\hline $\begin{array}{l}\text { 1. } 3 \text { method factors, } \\
5 \text { trait factors }\end{array}$ & & id not & converge; see & discussion) & \\
\hline $\begin{array}{l}\text { 2. } 3 \text { method factors, } \\
2 \text { trait factors }\end{array}$ & 203 & 80 & 2.54 & .051 & .932 \\
\hline $\begin{array}{l}\text { 3. I general factor (no } \\
\text { method or trait factors) }\end{array}$ & s) 741 & 90 & 8.23 & .066 & .751 \\
\hline $\begin{array}{l}\text { 4. } 3 \text { method factors, } \\
\text { no trait factors }\end{array}$ & 288 & 87 & 3.31 & .044 & .903 \\
\hline $\begin{array}{l}\text { 5. } 5 \text { trait factors, } \\
\text { no method factors }\end{array}$ & 590 & 80 & 7.38 & .069 & .802 \\
\hline $\begin{array}{l}\text { 6. } 3 \text { method factors, } \\
1 \text { general factor \& } \\
\text { no trait factors }\end{array}$ & 151 & 72 & 2.10 & .027 & .950 \\
\hline
\end{tabular}


ing and mathematics achievement are substantially correlated, the two sets of measures assess distinct attributes. The clearest distinction between reading and math scores occurs for student self-concepts in these two areas (mean $r=.02$ ). Reading selfconcepts are substantially correlated with reading measures, but not with math measures. In contrast, math self-concepts are substantially correlated with math measures, but not with reading measures. This pattern of results, using the same logic as in the MTMM analyses described earlier, demonstrates that the reading and math scores are measuring distinguishable constructs. Thus, while the SDRT subscales do not distinguish between the reading traits that the test claims to measure, the SDRT summary score does agree with other reading measures and can be distinguished from mathematical achievement.

\section{Discussion}

In both studies the SDRT summary scores were substantially correlated with other overall reading measures and were distinct from measures of mathematical achievement, and there was good evidence for the convergent validity of the SDRT subscales. However, the reading traits claimed to be measured by the SDRT showed no discriminant validity and this failure was demonstrated in comparisons between scores on the SDRT and teacher ratings, between ratings by the same teacher on different occasions, and even between scores for the SDRT administered at separate times. This lack of discriminant validity was apparent in the application of the Campbell-Fiske guidelines, but it was more clearly demonstrated with the CFA analyses where the data could be explained by a method/ halo effect and an overall reading factor that reflected all the measured variables.

These results demonstrate that while the 1966 version of the SDRT may have validity as an overall measure of reading, its ability to differentiate among the subscales that it claims to measure is clearly refuted. Since the purpose of a diagnostic test is to differentiate strengths and weaknesses in particular areas and not just to provide an overall performance measure, this version of the SDRT has no apparent value as a diagnostic test. The force of these conclusions must be tempered since a new version of the SDRT has been developed, even though the 1966 version of the SDRT is considered to be a well-constructed test (Anastasi, 1976).

The strength of the general reading factor may support the contention that reading effectiveness can best be viewed as a unitary construct or holistic process, and that the attempt to separate it into specific components may be counterproductive. Alternatively, it may support Anastasi's (1976) contention that the diagnosis of reading problems requires a trained specialist who conducts an intensive clinical case study and collects a broad array of information. Superficially, this suggestion seems laudable, but it is still necessary to demonstrate that information from such an effort can be used to define distinct components of reading that have diagnostic value, and these claims should also be evaluated with MTMM designs.

An important consideration in the design of MTMM studies is the choice of method variables. For example, these results suggest that teachers cannot differentiate among traits that the SDRT claims to measure. Although this may limit the usefulness of the SDRT, the problem could be with the teacher ratings, and support for the discriminant validity of the SDRT subscales might be demonstrated if another criterion were selected. However, the lack of discriminant validity in the SDRT subscales was also demonstrated for comparisons between Levels I and II of the same test, and it makes no sense to argue that this is not an adequate criterion. The demonstration of discriminant validity based on two different forms of the same test would provide only weak support for the test's ability to differentiate between the traits that it claims to measure, but the failure to demonstrate discriminant validity with this comparison provides strong evidence against the test's discriminant validity.

Ideally, the design of MTMM studies for the evaluation of diagnostic tests should include (1) scores from the test; (2) scores from another form of the same test administered on a separate occasion (alternatively a retest with the same test, or even split-halves representing each of the subscales measured with the same test); and (3) a parallel set of 
scores that measure the same traits with an entirely different method (e.g., ratings by the teacher, a trained expert, or even self-ratings by the subject) that are also collected on two separate occasions.

Comparisons based upon similar methods (e.g., two sets of test scores from the same test, or two sets of ratings by the same person) provide a weak test of the discriminant validity of the traits, but the failure of such comparisons would provide strong evidence against their discriminant validity. Comparisons based upon dissimilar methods (e.g., ratings and test scores) provide a more demanding assessment of discriminant validity, but the failure of such tests would not necessarily mean that the test would fail if another external criterion had been selected. Thus, the consideration of either type of comparison by itself may provide valuable information, but it also has potential limitations. The examination of both types of comparisons within the context of the same study provides a better basis for evaluating the discriminant validity of a diagnostic test. The simultaneous consideration of multiple sources of method error within the same analytic framework is also consistent with other methodological advances in measurement theory (e.g., generalizability theory; see Cronbach, Gleser, Nanda, \& Rajaratnam, 1972), and further refinement of this approach will constitute an important extension to the usefulness of MTMM designs.

\section{References}

Anastasi, A. (1976). Psychological testing (4th ed.). New York: Macmillan.

Bentler, P. M., \& Bonett, D. G. (1980). Significance tests and goodness-of-fit tests in the analysis of covariance structures. Psychological Bulletin, 88, 588606.

Butler, S., \& Marsh, H. W. (1983). Reading and arithmetic achievement in primary grades for students from English and non-English speaking families: A seven year longitudinal study. Sydney, Australia: University of Sydney, Department of Education.

Butler, S., Marsh, H. W., Sheppard, M. J., \& Sheppard, J. L. (1982). Early prediction of reading achievement with the Sheppard School Entry Screening Test: A four year longitudinal study. Journal of Educational Psychology, 74, 280-290.
Butler, S., Marsh, H. W., Sheppard, M. J., \& Sheppard, J. L. (1983). Prediction reading achievement from kindergarten to third grade: Implications for screening. Australian Journal of Education, 27, 288-303.

Butler, S., Marsh, H. W., Sheppard, M. J., \& Sheppard, J. L. (in press). A seven year longitudinal study of early prediction of reading achievement. Journal of Educational Psychology.

Campbell, D. T., \& Fiske, D. W. (1959). Convergent and discriminant validation by the multitrait-multimethod matrix. Psychological Bulletin, 56, 81-105.

Coles, G. S. (1978). The learning-disabilities test battery: Empirical and social issues. Harvard Educational Review, 48, 313-340.

Cronbach, L. J. (1970). Essentials of educational testing (3rd ed.). New York: Harper \& Row.

Cronbach, L. J., Gleser, G., Nanda, H., \& Rajaratnam, N. (1972). Dependability of behavioral measurements. New York: Wiley.

Fornell, C. (1983). Issues in the application of covariance structure analysis: A comment. Journal of Consumer Research, 9, 443-448.

Jöreskog, K. G. (1969). General approach to confirmatory maximum likelihood factor analysis. Psychometrika, 34, 183-202.

Jöreskog, K. G. (1974). Analyzing psychological data by structural analysis of covariance matrices. In $R$. C. Atkinson, D. H. Krantz, \& R. D. Supes (Eds.), Contemporary developments in mathematical psychology (vol. 1, pp. 1-56). San Francisco: W. H. Freeman.

Jöreskog, K. G., \& Sörbom, D. (1981). LISREL V: Analysis of Linear Structural Relations By the Method of Maximum Likelihood. Chicago: International Educational Services.

Karlsen, B., Madden, R., \& Gardner, E. R. (1966).Stanford Diagnostic Reading Test, Level I, Level II. New York: Harcourt, Brace, and World.

Kasdon, L. M. (1972). [Review of Stanford Diagnostic Reading Test.] In O. K. Buros (Ed.), The mental measurements yearbook (7th ed.; pp. 1127-1129). Highland Park NJ: Gryphon Press.

Kenny, D. A. (1979). Correlation and causality. New York: Wiley.

Marsh, H. W., Barnes, J., \& Hocevar, D. (in press). Self-other agreement on multidimensional self-concept ratings: Factor analysis and multitrait-multimethod analysis. Journal of Personality and Social Psychology.

Marsh, H. W., \& Hocevar, D. (1983). Confirmatory factor analysis of multitrait-multimethod matrices. Journal of Educational Measurement, 20, 231-248.

Marsh, H. W., \& Hocevar, D. (1984). The factorial invariance of students' evaluations of college teaching. American Educational Research Journal, 21, 341366. 
Marsh, H. W., Smith, I. D., Barnes, J., \& Butler, S. (1983). Self-concept: Reliability, dimensionality, validity, and the measurement of change. Journal of Educational Psychology, 75, 772-790.

McLeod, J. (1977). GAP Manual: Reading Comprehension Test. Richmond, Australia: Heinemann Educational.

Schmitt, N., Coyle, B. W., \& Saari, B. B. (1977). A review and critique of analyses of multitrait-multimethod matrices. Multivariate Behavioral Research, $12,447-478$.

Schonell, F. J., \& Schonell, F. E. (1955). Schonell Reading Test. London: Oliver \& Boyd.

Thorndike, R. L., \& Hagen, E. P. (1977). Measurement and evaluation in psychology and education (4th ed.). New York: Wiley.

van Roekel, B. H. (1978). [Review of Stanford Diagnostic Reading Test.] In O.K. Buros (Ed.), The mental measurements yearbook (8th ed.; pp. 1298-1300). Highland Park NJ: Gryphon Press.

\section{Acknowledgments}

The authors express appreciation to Jennifer Barnes for her comments on drafts of this paper, and to John and Marlene Sheppard for their assistance in conducting the research. Financial support for the project came from the Australian Research Grants Committee, Sydney University Research Grants, Butler Airways, and the New South Wales Department of Education.

\section{Author's Address}

Send requests for reprints or further information to Herbert W. Marsh, Department of Education, University of Sydney, Sydney, NSW 2006, Australia. 